\title{
Finding the Probability of Doors Being Open Using a Continuous Position Logger
}

\author{
KEVIN FRANK ${ }^{1}$, MICHAEL SPEARPOINT ${ }^{1}$, and STEVE WEDDELL ${ }^{2}$ \\ ${ }^{1}$ Department of Civil and Natural Resources Engineering \\ University of Canterbury \\ Christchurch, New Zealand \\ ${ }^{2}$ Department of Electrical and Computer Engineering \\ University of Canterbury \\ Christchurch, New Zealand
}

\begin{abstract}
Data for the probability that a doors are open or closed in the event of a fire is sparse. The literature only presents a snap-shot rather than how the position of the door has changed over time. This paper describes the development of a low-cost, unobtrusive logging device that can continuously monitor the position of a door for extended periods. The devices were used to record 180 days of data from 52 doors located in different types of sleeping occupancies: hotels, apartments, dormitories and rest homes. Results were obtained for the probability that doors were open during day-time and night-time; and also during weekdays and weekends. Overall a probability distribution for the fraction of time that a door was found to be open is an inverse Gaussian function with mean $\mu=0.104$ and shape factor $\lambda=0.0117$.
\end{abstract}

KEYWORDS: door, human factors, reliability

\section{NOMENCLATURE}

m

$$
\text { magnetic field vector (gauss) }
$$

Greek

$\phi \quad$ angle between the vertical axis and the magnetic field $\left(^{\circ}\right)$

$\theta \quad$ angle between the $\mathrm{x}$ and $\mathrm{z}$ components of the magnetic vector $\left(^{\circ}\right)$

\begin{tabular}{ll}
\multicolumn{2}{l}{ subscripts } \\
$x$ & axis parallel to door plane \\
$y$ & vertical axis \\
$z$ & axis perpendicular to door plane \\
1 & door position 1 \\
2 & door position 2
\end{tabular}

subscripts

$x \quad$ axis parallel to door plane

door position 1

\section{INTRODUCTION}

\section{Background}

While effectiveness and reliability are commonly associated with active systems such as sprinkler or smoke management systems, passive compartmentalisation components are also subject to failure due to a number of factors. A few of the most common are propped-open doors; improperly fire stopped holes cut through walls, ceilings, or floors for building services; and open windows. Compartmentalisation is critical for fire safety because it determines how much oxygen is available for the fire through ventilation and the available paths for fire products to spread out of the compartment of fire origin. In addition, an open door, window, or other penetration in a compartment boundary can adversely affect the operation of a smoke control system [1].

Much work has been done on structural fire engineering that focusses on how long a particular passive element such as a door will stand up to a severe thermal insult typically associated with fully-developed fires. When considering the early stages of the fire, the primary concern is the status and integrity of the passive compartmentalisation prior to the fire. Specifically for doors the issue is whether they are fully or only partially open; or closed. For example, Palmer [2] compared the fire risk between sleeping in a typical house bedroom with the bedroom door open and closed and found that fire risk was reduced with a closed bedroom door. Similarly Lustig [3] examined the status of doors and windows in 250 fires in dwellings in the UK over a period of five years in the 1950s. While there was not enough information gathered by Lustig to statistically determine the effects of open windows and doors on fire development, specific case histories indicated that closed doors and windows had a significant effect on fire development. In three cases, a fire 
ignited but either burned out or was undetected in a closed room and did not damage other areas of the residence. In two cases, it was noted that open doors allowed fire to spread rapidly. In one case, a fire on the first floor of a dwelling spread upstairs through open doors to two bedrooms, where four people died. There were two people rescued from a room on the first floor where the door was closed. Lustig also noted two examples where a closed door prevented early discovery of the fire.

Doors can be categorised by their motion; whether swinging (hinged), sliding or rolling; their method of operation; fully manual (both open and closed), automatic door closer (spring operated, motorised, gravity system) or automatic hold open device (magnetic); and their ability to prevent fire and smoke spread; whether unrated, smoke stop or fire rated. Observations from buildings during this research found that the most common type of smoke stop or fire door in residential and commercial occupancies is the swinging door, in either single leaf or double leaf configurations, with self closers, with or without automatic hold open devices.

In most cases for the purpose of fire modelling, doors that are not expected to perform as smoke stop or fire doors will be considered to be open at all times, for example as specified in C/VM2 [4]. However with the development of performance-based methods from a probabilistic viewpoint then the likelihood of a door being open or closed should be considered. For example, the National Research Council of Canada (NRCC) has developed the Fire Cost Assessment Model (FireCAM) for demonstrating the ability of designs to meet performance-based regulations in residential and office buildings. This probabilistic/deterministic tool considers six design fire scenarios in the room of fire origin: smouldering, non-flashover, and flashover fires; each with the door open or closed [5]. Each design fire is assigned a probability and passive feature effectiveness is considered in the probability that the door to the fire compartment is open or closed. In a similar vein, the B-RISK zone model [6] allows the modeller to specify the probability of a door being initially closed, the reliability of hold open devices, along with user-defined door opening and closing times. The application of these models therefore needs relevant door reliability data to be made available.

\section{Existing Data}

Bukowski et al. [7] noted that there was very little data regarding performance of individual passive elements, although there are two sets of expert surveys cited that indicate probabilities that an opening will be fixed open; the Warrington Delphi UK study estimated the probability that an opening will be fixed open is $29 \%$, and the Australian Fire Engineering Guidelines estimated that the reliability of a passive element (such as a wall) should be reduced from $95 \%$ to $90 \%$ if an opening with an automatic closer is present. Quoting other unknown data sources, PD7974-7:2003 [8] indicates that up to $23 \%$ of fire doors are held open by some means that will not release in case of a fire, and of the hinged fire doors that are not blocked open, $20 \%$ may fail to close correctly.

Yashiro et al. [9] reported estimates of the reliability of fire doors with automatic closers and inter-lock devices, as well as fire shutters using Tokyo Fire Department data. Fire doors with automatic closers were estimated to be $97 \%$ reliable, $91 \%$ reliable when inter-lock devices were used, and fire shutters were also estimated to be $91 \%$ reliable. Fernandez [10] noted that nuclear facility inspectors found fire doors propped open, however no quantitative data was reported. Testing conducted by Factory Mutual in the early 1990s indicated that the failure rate of fire doors including horizontal sliding doors on inclined tracks, horizontal sliding doors with counterweight closures, horizontal sliding doors with spring closures, vertical sliding doors, and swinging doors in Maximum Foreseeable Loss walls was $15 \%$ [11].

Ramachandran [12] discussed the status of fire doors in 28 buildings reported to be equipped with fire doors where large fires occurred during 1965 and 1966 in the UK. While door position data at the time of fire was only available for 19 of the fires, it was found that fire doors were open in 5 fires, or $26 \%$ of the fires with known door positions. A 1970 study by Langdon Thomas and Ramachandran [13] looked at data on fire doors propped open provided from fire brigade inspection visits in the UK. A summary of the results of their study is shown in Table 1. 
Table 1. Frequency of doors observed to be propped open from 1973 UK study [13].

\begin{tabular}{rcc} 
Occupancy & Number of doors observed & \% propped open \\
\hline Dwellings & 9,887 & 17 \\
Office buildings & 7,055 & 18 \\
Institutional buildings & 15,558 & 39 \\
Schools & 14,102 & 23 \\
Shops and department stores & 3,371 & 26 \\
Assembly buildings & 18,435 & 5 \\
Factory buildings & 22,491 & 15 \\
Storage buildings & 1,010 & 37 \\
\hline Total doors / Average propped open & $\mathbf{9 1 , 9 0 9}$ & $\mathbf{1 9}$
\end{tabular}

A major disadvantage of the existing data on door reliability is that it is typically compiled from inspection data. This approach provides a "snapshot" of the position of the door in time but does not provide information on how the position of the door has changed over time. For example, a door might be propped open at certain times of the day when it is heavily used. The propensity of occupants to prop open a door might be seasonally dependent or day-of-week dependent if the usage of the building varies over these time periods.

\section{DOOR POSITION DATA LOGGER DESIGN}

Since existing data on door reliability is limited, a new device for collecting data on door position has been developed. It consists of a low cost, unobtrusive data logging device capable of collecting several months of door position data. The layout of the major components in the devices can be seen in Fig. 1. The device needed to be physically small, be as cost-effective as possible, be able to record data over long periods, give reliable measurements to a required level of accuracy; and be simple to set up, monitor and extract data.

Data from the device may be useful for a variety of stakeholders. Persons developing building regulations or fire safety practitioners using performance-based design might use the reliability data to determine the contribution of fire and smoke doors for reducing the spread of fire and smoke through buildings. Fire door and door closer manufacturers might be interested in collecting data on their devices to determine usage patterns. Building managers may be interested in knowing the usage patterns of doors in their buildings. Fire safety researchers who examine human factors in fire may also be interested in data on the use of doors during evacuation or fire fighting. Some data has been collected during trial evacuations in buildings but this data is outside the scope of this paper.

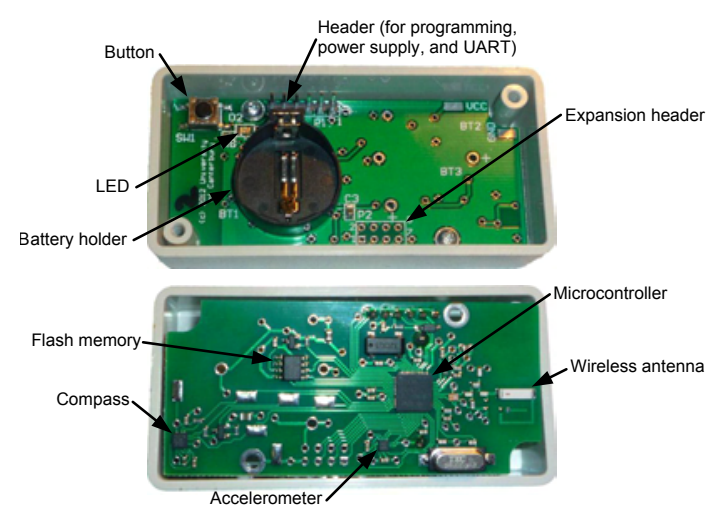

(a)

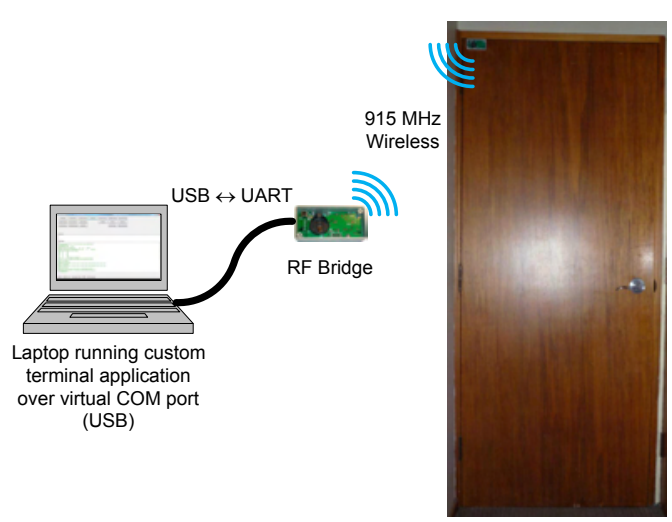

(b)

Fig. 1. Final design of the door data logging device: (a) Major components used in the door position logging device; (b) Door position data logging device interface. 


\section{Microcontroller and Interface}

The Texas Instruments MSP430 family of microcontrollers has been selected based on power consumption, price, and ease of programming. The Texas Instruments CC430F5137 has an onboard radio for wireless interfacing, a low power mode that keeps the real time clock active, retains the contents of RAM, and allows interrupts to be monitored, with a power consumption of $2 \mu \mathrm{A}$.

The logging device has been set up to communicate wirelessly with an RF bridge device at $915 \mathrm{MHz}$ at $250 \mathrm{kbps}$ (kBaud). This RF bridge, which also utilises the CC430F5137 microcontroller, then communicates to a PC via the CC430 Universal Asychronous Receiver/Transmitter (UART) peripheral and a FTDI UART to USB converter. Communication is initiated by pressing a button on the data logging device which signals the microcontroller to switch from "normal" mode (or the data logging configuration) to "debug" mode (the communication configuration). The data logging device is returned to normal mode by either a timeout or a command from the PC to disconnect the device.

The $32.768 \mathrm{kHz}$ crystal oscillator specified has a frequency tolerance of $\pm 20 \mathrm{ppm}$ at $25^{\circ} \mathrm{C}$, which corresponds to a microcontroller clock accuracy of $\pm 2 \mathrm{~s}$ per day, or \pm 6 minutes over the intended 6 month data acquisition period. The crystal has a minimum temperature $(T)$ frequency coefficient $\beta$ of $-0.04 \mathrm{ppm} / T^{2}$, so a change of $10^{\circ} \mathrm{C}$ can cause the frequency to change by approximately $4 \mathrm{ppm}$. The interior ambient temperature in the buildings monitored would not be expected to vary by more than $10^{\circ} \mathrm{C}$ to $30^{\circ} \mathrm{C}$. It has been found that the time drift remained essentially linear during a 45-day test measurement period and although the temperature was not tracked during this time, it was noted to fluctuate as expected for a typical office environment. Thus the time drift during field data collection is assumed to be linear as well and only two points were recorded, prior and after data collection.

A custom terminal program has been written using VB.NET to send and receive information from the PC to the data logging devices. The use of a custom terminal program reduces the amount of time required to set up and download data from the devices. A particular advantage is the ability to syncronise the real time clock on the devices with a laptop clock using a single mouse click rather than manually entering the time.

\section{Sensors}

Several different types of sensors to measure the door position have been considered. The first option was a rotary potentiometer, measuring the door angular rotation using the potentiometer's variable resistance in a voltage divider. This would have required a fixture to be designed for the potentiometer at the pivot point of the door, perhaps mounted on one of the door hinges. A second option was a capacitive distance measuring sensor, which would have required two plates mounted on the door and frame to measure the change in capacitance as the plates moved away from each other. Other proximity sensors such as optical sensors or ultrasonic sensors could be used but the signal could get blocked by interfering objects. Gyrometers, which measure rate of rotation, could have been used by integrating the rate of rotation over time. This option was discarded due to the potential for cumulative integration errors over time. Magnetometers used as a compass to measure the door's angular position relative to the geomagnetic field has been the option selected. The advantage of the magnetometer approach is that the sensor could be mounted anywhere on the door, and does not require an additional fixture on the door frame or adjacent wall. Also the orientation measured by the magnetometer or compass is independent of time, although a potential disadvantage is erroneous readings due to nearby objects influencing the magnetic field.

Investigation into the cost of the sensors found that the price of surface mount electronic magnetometers is reasonable, likely due to their widespread use in smart phones and navigational devices. The magnetometer or compass selected is the Honeywell HMC5883L, a 3 axis magnetometer with low power consumption. The HMC5883L has a resolution of 1 to 2 degrees of rotation, depending on the strength and orientation of the geomagnetic field at the location where measurement is taking place. It takes $200 \mu$ s to turn on, and a further $6 \mathrm{~ms}$ to be able to send data. A data ready interrupt pin can be monitored to ensure that data is sent as soon as the device is ready. The device draws approximately $100 \mu \mathrm{A}$ in measurement mode.

To optimize memory and power requirements, the Bosch BMA250 3 axis accelerometer has been selected, which can be used in a motion sensing configuration to allow the rest of the circuitry to remain at idle while the 
door was stationary. The resolution of the BMA250 on the minimium scale setting two times the acceleration due to gravity $(2 \mathrm{~g})$ is $256 \mathrm{bits} / \mathrm{g}$, or $0.038 \mathrm{~m} / \mathrm{s}^{2}$. The accelerometer uses $7 \mu \mathrm{A}$ in low-power mode with a sleep duration of $25 \mathrm{~ms}$ (time between samples) using unfiltered data.

The accelerometer has a variety of interrupt-trigger modes; the slope detect and high-g have been evaluated for indicating door motion. The threshold, duration, and axes utilized for both modes could be set by the user. The slope detection method triggers the interrupt when the change in acceleration exceeded a user-defined threshold for a user-defined duration. The high g-force method triggers the interrupt when the magnitude of the acceleration exceeded a user-defined threshold for a user-defined duration. Both methods are used on the $\mathrm{z}$ axis of the accelerometer. Unfortunately, it has been found that the accelerometer interrupt provides excessive spurious signals unless the low pass filter is set to $8 \mathrm{~Hz}$. To acquire enough signals to filter the data to $8 \mathrm{~Hz}$ requires the accelerometer to be on for $64 \mathrm{~ms}$ for each slope calculation, which causes the current consumption to increase above $100 \mu \mathrm{A}$. This means that the accelerometer uses more power than the compass for measurement. The accelerometer does not provide a reduction in power consumption for longterm data collection where high temporal resolution is not required. The accelerometer could be removed for a cost saving, or a mechanical low pass filter mounting system could be designed to get more use out of the accelerometer. However, the accelerometer is still useful in devices where increased temporal resolution is desired.

The accelerometer and magnetometer are oriented to produce $\mathrm{x}, \mathrm{y}$, and $\mathrm{z}$ output. The magnetometer is located on a corner of the board as far away from other components (particularly the battery) as possible to reduce circuit electromagnetic and component ferromagnetic effects on the measured magnetic field.

\section{Data storage}

A 4 Mbit flash memory chip (Atmel AT25DF041A) is chosen based on the expected memory requirements. The flash uses a maximum of $10 \mathrm{~mA}$ to read data and $18 \mathrm{~mA}$ to write data. As the flash memory is non-volatile, the maximum amount of data that could be lost in the event of a power disruption or microcontroller reset is the contents of the RAM, a maximum of 128 data points if the RAM is completely full. A microcontroller reset can be identified in the data because the first flash page recorded after a reset has the reset date (January $1,2000)$ recorded as the first value.

In order to compress the data storage requirements for each recorded sample, three data types are used: position data, 15 minute time recordings, and daily time recordings. Each data point is limited to a 16 bit word. Two bits are used to indicate the type of data stored. For the position data, 4 bits are consumed with the door position. The remaining 10 bits are used for a time stamp with one second resolution. If a sample is taken in the preceding 15 minutes, a 15 minute time stamp is recorded to indicate that the preceding values has been recorded during that 15 minute interval of the day. At midnight the day and month are recorded, followed by a 12 bit battery voltage reading.

The 4 Mbit flash memory is split into 2,048 256 byte (128 word) pages. The first page is reserved for storing the total number of flash pages used and other calibration data if required, leaving 2,047 pages capable of storing 128 words each, or 262,016 potential data points. Based on 180 days of testing, 360 data points are consumed with midnight and battery data storage. Assuming $100 \%$ of the 15 minute intervals are recorded, another 17,280 data points are required, leaving 244,376 points for door position data, or a maximum average of 1,357 door position data points per day. Assuming that the average door opening event takes $6 \mathrm{~s}$ or consumes an average of three data points, an average of 450 door movement events per day can be captured using the devices over the 180 day testing period.

\section{Power source}

To keep the size, weight, and cost of the door logging device down, a CR2032 primary lithium ion "coin" battery is selected. This can supply approximately $180 \mathrm{mAh}$ of current before dropping below the minimum voltage required by the flash memory. The device board has additional through-hole connections to add another CR2032 or CR2450 (620 mAh capacity) battery holder in parallel. The enclosure is also big enough to fit one of these additional batteries. However, the presence of the additional battery offsets the compass measurements because of their proximity to the compass. Power consumption tests indicate that with a $27 \mu \mathrm{A}$ 
average current draw, the devices will last for approximately 9 months, not including flash page writes and wireless connections. If the battery voltage is too low to support radio operation when data is collected, a $3 \mathrm{~V}$ power supply such as an external battery pack can be connected to boost the power supply without losing data stored to RAM.

\section{Manufacture}

The boards were custom manufactured and a stencil was used to apply solder paste to the boards. Assembly was completed at the University over a period of approximately 1 week. A pick-n-place machine was used to place surface mount components which were then soldered with a reflow oven. Through-hole components were hand soldered.

A $40 \mathrm{~mm} \times 80 \mathrm{~mm} \times 20 \mathrm{~mm}$ plastic ABS box has been selected for the enclosure as it is adequate to house the device while being small enough to be unobtrusive and lightweight enough to be easily supported by adhesive poster strips. The strips have to secure the device to doors adequately by supporting the weight of the device which was $40 \mathrm{~g}$, including battery but not permanently damage or alter the doors.

The cost per individual device (at early 2012 prices) was \$NZ 38.75 but by building over 100 units reduced the unit cost to around \$NZ 27.20 each. Further discounts were available for larger quantities but the scope and budget of the project would not allow expanded production.

\section{Magnetometer calibration}

Magnetometer output can be influenced by nearby objects such as ferromagnetic material or electronic equipment. Typical effects have been described as "hard iron" where a constant magnetic field is added to the geomagnetic field by a proximal ferromagnetic material and "soft iron" where a nearby magnetic material distorts the geomagnetic field [14]. Hard and soft iron effects are observed in magnetometer output by a shift or distortion, respectively.

Seven of the devices have been randomly selected and tested at different locations on an office door at the University. One device has been tested with single and dual battery configurations to characterise the effect of a battery adjacent to the compass. The battery is noted to shift the magnetic field measured in both the $\mathrm{x}$ and $\mathrm{z}$ directions. A function to offset individual magnetometer axis output by a constant amount for the angle calculation has been added to compensate for this behaviour. The magnetic field measured at each device location on the door is stable with time but it varies between locations on the door. Mounting positions near the hinge are observed to provide a more consistent magnetic field, represented by a monotonically changing elliptical output from the magnetometers over the door travel path, likely due to the reduced travel of the magnetometer relative to magnetic field affecting objects nearby. The optimal position for accelerometer output is as far from the hinge as possible to amplify the acceleration of the device. Balancing the location to provide acceptable output from the two sensors is difficult but since the accelerometer output is not critical for long-term monitoring the devices have been mounted close to the door hinge.

The measured $\mathrm{x}, \mathrm{y}$, and $\mathrm{z}$ components of the magnetic field are shown graphically in Fig. 2. Assuming the magnetic field remains constant as the compass rotates in the $x-z$ plane, the y component remains constant and the measured $\mathrm{x}$ and $\mathrm{z}$ values reflect the angle of the door to the magnetic field. As direct recording of the raw data is memory intensive, 16 discrete door opening angles are calculated to reduce the memory requirement for each door position to 4 bits. The dot product of the measured magnetic field vectors is used to calculate the angle as

$\Delta \theta=\cos ^{-1} \frac{\mathbf{m}_{1} \bullet \mathbf{m}_{\mathbf{2}}}{\left|\mathbf{m}_{\mathbf{1}}\right|\left|\mathbf{m}_{\mathbf{2}}\right|}$

which always provides a positive angle from the reference vector (in this case, corresponding to the door shut position). A discrete door angle data point is obtained by dividing the calculated angle by the angle calculated for a fully open door $\left(90^{\circ}\right.$ ), resulting in 16 data points from $0^{\circ}$ (position 0 , door shut) to $90^{\circ}$ (position 15). Any door opening angle past $90^{\circ}$ is recorded as $90^{\circ}$. The method is able to handle the complex magnetic field behaviour noted when the devices are mounted away from the door hinge. 


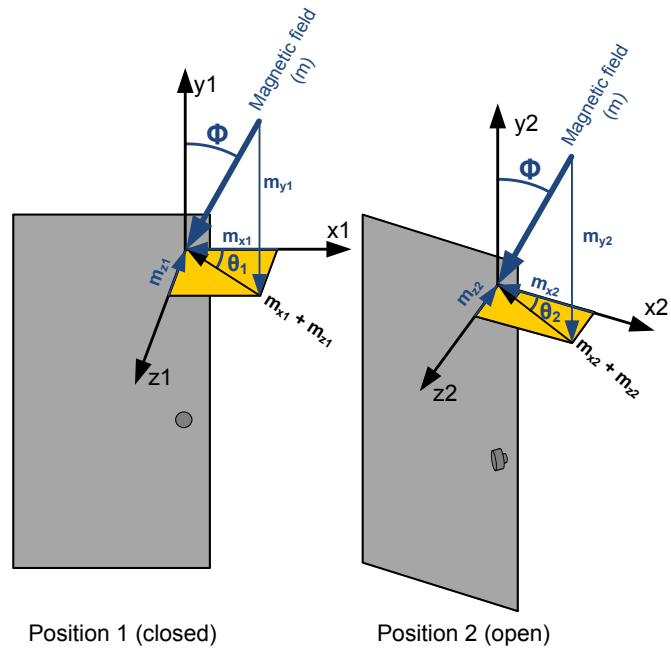

(a)

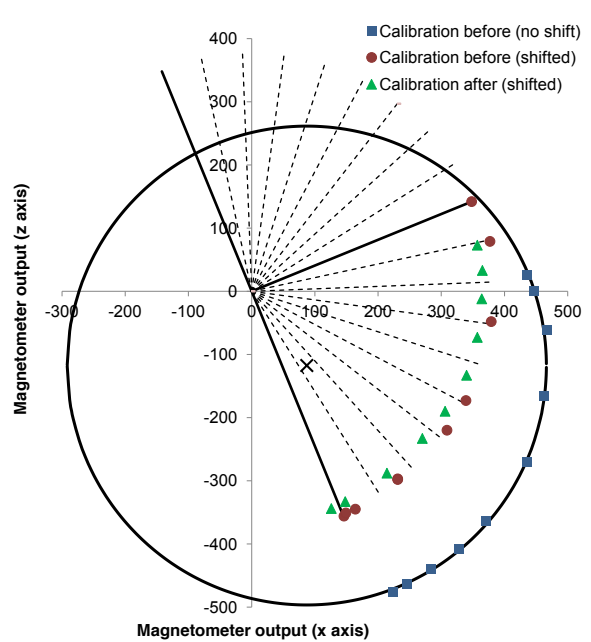

(b)

Fig. 2. Conversion of compass raw output to angle: (a) Determination of angle using the $\mathrm{x}, \mathrm{y}$, and $\mathrm{z}$ magnetic field magnitude output; (b) Field calibration.

When the devices are initially installed on a door, positive and negative magnetometer self tests are run. The self test imposes an internally generated magnetic field on each axis and records the change in output which indicates if the magnetometer is operating properly. An initial test sequence is subsequently conducted by recording 10 data points through the range of motion of the door. To improve the accuracy of the angle calculation by compensating for hard iron effects, a circle is fit to this data using the least squares method described by Bullock [15]. The output is then shifted so the output is centered at zero for both $\mathrm{x}$ and $\mathrm{z}$ axes. A second set of 10 data points is then taken to establish the calibrated output of the magnetometer. Soft iron effects have been evaluated by considering the fit of the circle and the shifted output compared to radial lines drawn in $10^{\circ}$ increments to $90^{\circ}$ in both directions. After data collection, a final set of data points is taken over the full door motion to determine if the magnetometer output has remained stable over the data collection period.

To conserve memory, door position data is only recorded if the measured position of the door changed. It is observed that if the door is in a position where the measured magnetic field is near the transition between two calculated discrete angles additional "noise" data points are recorded. To address this issue, the door position is calculated in 32 increments and only recorded if it changes by an absolute increment of greater than one. The value recorded is then the calculated position divided by two.

Example data output from one of the devices during a trial evacuation in a University of Canterbury building is shown in Fig 3. Data for a group of people passing through the door and a single person passing through is shown. 


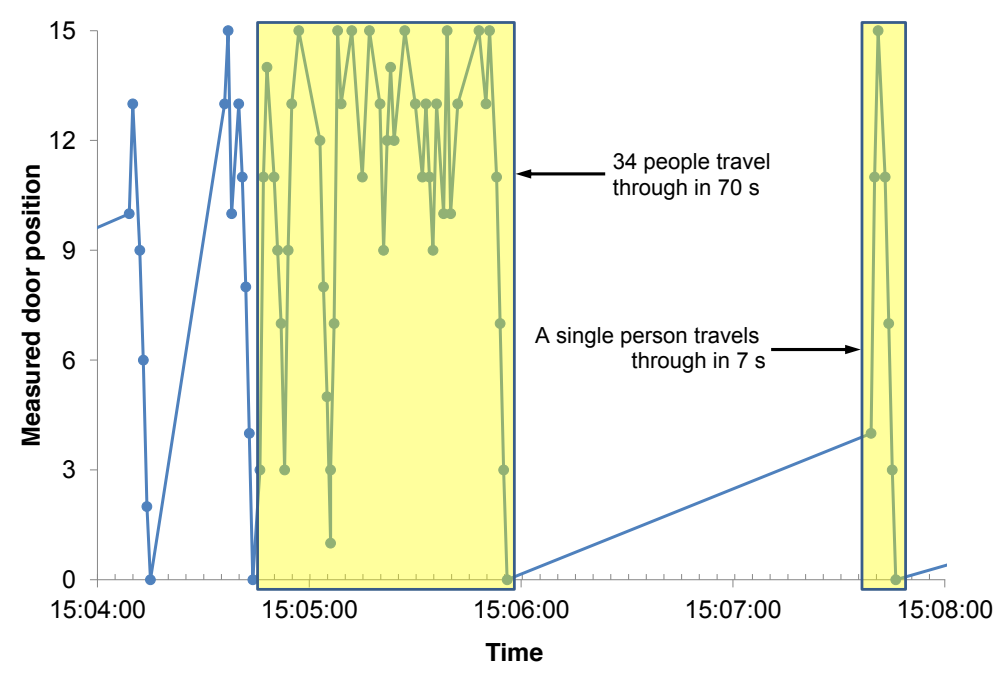

Fig. 3. Door data collected during a trial evacuation of a University of Canterbury building.

\section{DOOR RELIABILITY DATA COLLECTION}

\section{Building and door selection}

In New Zealand, building inspections are completed as part of the annual Building Warrant of Fitness requirements by an Independently Qualified Person (IQP) or Licensed Building Practitioner [16]. The requirements for inspection of specified systems including those that relate to means of escape from fire are set out in a document known as a Compliance Schedule. Specified systems for escape from fire include electromagnetic or automatic doors or windows [17].

Doors were identified for monitoring through the assistance of a company based in Christchurch that designs, installs, and services fire protection systems, and also provides inspection services for Building Warrant of Fitness purposes. The scope of the study has been limited to sleeping occupancies because open doors are most likely to have an adverse effect on life safety in these types of buildings. Doors were selected in buildings in the Christchurch and North Canterbury areas. A list of the building types and number of door leaves monitored in each type of building is shown in Table 2.

Table 2. A summary of the building types and number of doors studied.

\begin{tabular}{rcc} 
Type of building & Number of buildings & Number of door leaves \\
\hline Hotel/backpackers & 6 & 32 \\
Apartment/condo & 2 & 5 \\
Boarding house/dorm & 2 & 7 \\
Rest home & 3 & 8 \\
\hline Total & $\mathbf{1 3}$ & $\mathbf{5 2}$
\end{tabular}

The selected doors were $0.8 \mathrm{~m}$ to $1.0 \mathrm{~m}$ wide hinged doors that formed part of the shared means of escape for the buildings; single household unit doors were not included. Of the doors considered, 9 had fire door signage, 10 had smoke control door signage, and 33 did not have visible signage indicating the type of door. With the exception of two doors, doors with self-closers only (no approved hold-open devices) were selected because the door logging devices could not differentiate whether the hold-open device was operating properly or not. This does not mean that hold-open devices do not fail. Anecdotal evidence from the inspection company indicated that doors with hold-open devices had been observed to fail due to lifted carpets or objects placed in the path of the door swing. It is also possible for a hold-open device to fail due to a malfunctioning detection system. During the door selection process it was noted that the majority of shared means of escape doors in 
sleeping occupancies in the selected building population did have approved hold-open devices, limiting the potential population of doors for the study. Door failures were noted during the deployment of the devices; four examples are shown in Fig. 4. The majority of the failures were propped open doors; a single door was found with a disconnected closer. It was noted anecdotally that double sets of doors such as shown in Fig. 4(b) were propped open as readily as single doors.

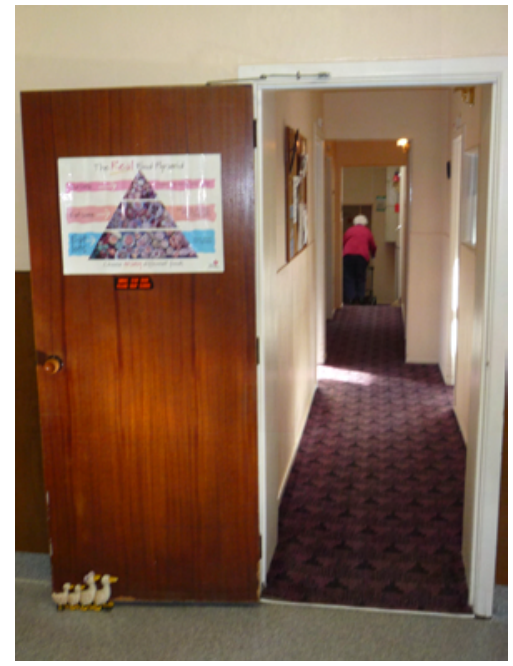

(a)

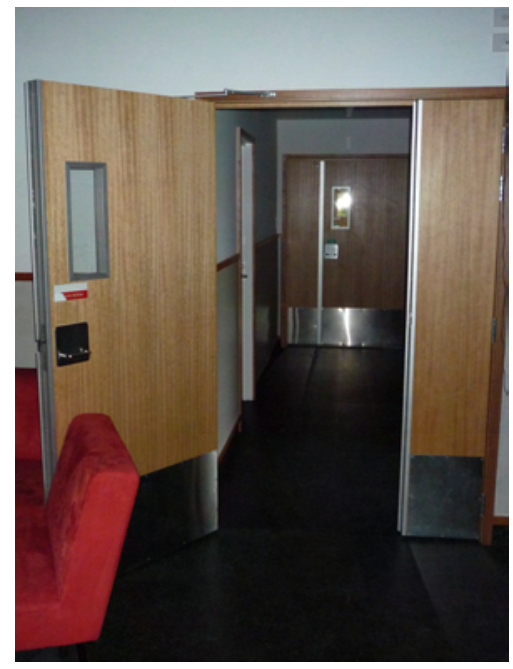

(c)

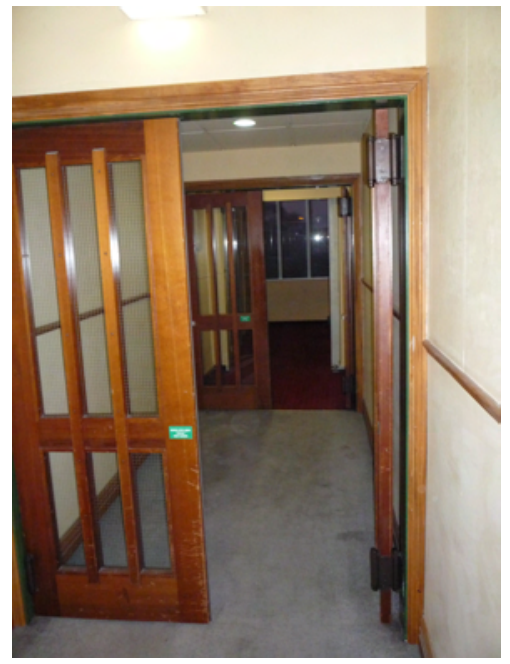

(b)

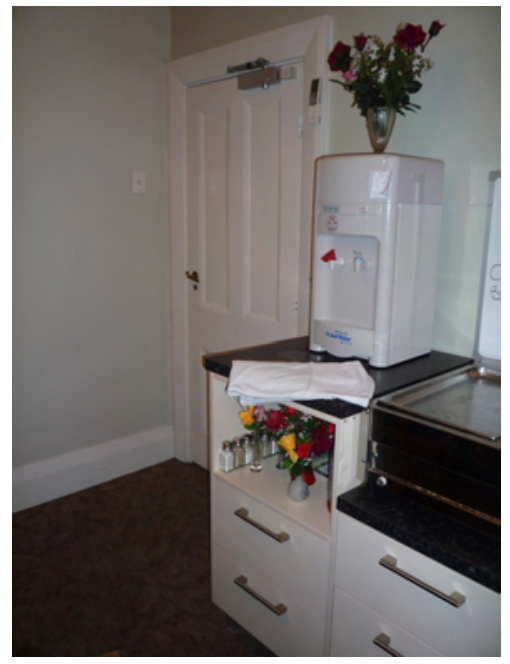

(d)

Fig. 4. Door failures noted during study: (a) Propped open; (b) Wedged open $(\times 2)$; (c) Propped open; (d) Disconnected closer.

\section{Results}

To distill the 16 position door output data into a single summary figure for the probability that a door was open at any time, the time that each door was positioned at the "2" or greater position is summed and divided by the total data collection time. The probability distribution for the fraction of time that a door was open is shown in Fig. 5. The best-fit distribution was an inverse Gaussian function with mean $\mu=0.104$ and shape factor $\lambda=0.0117$. The Kolmogorov-Smirnov value for this distribution is 0.118 . This distribution is highly skewed to the left, indicating that the majority of doors were closed most of the time with a few that were propped open for long periods of time. 


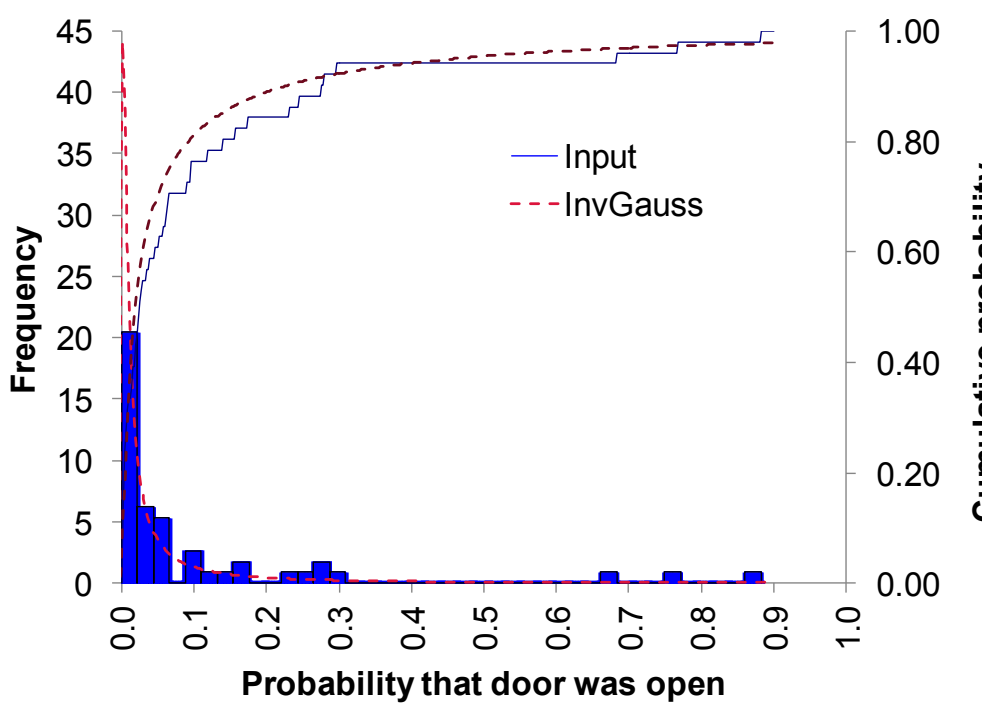

Fig. 5. The overall probability of a door being open from the 52 door sample, collected over 180 days.

Summary statistics for door reliability for each type of building and the total population are shown in Table 3 . Doors in the rest homes had the highest reliability and the least uncertainty, followed by the hotel/backpackers, apartment/condos, and boarding house/dormitories.

Table 3. Summary statistics for the overall door reliability for the 52 door sample.

\begin{tabular}{rcc} 
Type of building & Mean & St. dev. \\
\hline Rest home & 0.95 & 0.05 \\
Hotel/backpackers & 0.90 & 0.16 \\
Apartment/condo & 0.86 & 0.30 \\
Boarding house/dorm & 0.85 & 0.32 \\
\hline Total & 0.90 & 0.19
\end{tabular}

The collected data is split into nominal working hours from $0800 \mathrm{~h}$ to $1700 \mathrm{~h}$ and non-working hours from $1701 \mathrm{~h}$ to $0759 \mathrm{~h}$ to determine if there is an effect on the probability that a door was open or closed, shown in Table 4. There is a higher probability that a door was closed in the hotel/backpackers occupancy during non-working hours. A likely cause for this change is the use of the doors by cleaning staff during working hours. Otherwise, there is very little difference between working and non-working hours.

The data is also split into weekend days and weekdays, shown in Table 5. Again, there is very little difference other than a slight increase in the probability that doors were closed for the hotel/backpackers building type during the week, which likely reflects a lower usage of these types of buildings on weekdays. The probability that the 52 doors were closed is found to be higher than the 1970 UK study [13], which found $17 \%$ of dwelling doors (compare to probability of 0.86 for doors in apartment/condo buildings in this study to be closed), $23 \%$ of school doors (compare to 0.85 probability for boarding house/dorm doors to be closed in this study), and $39 \%$ of institutional doors (compare to 0.95 probability for rest home doors to be closed in this study) to be propped open.

The mean number of times that doors were opened for specified time intervals and the cumulative amount of time that the door was open when opened for those specific time intervals are shown in Figs 6 and 7, respectively. The total number of times that doors were opened ranged from 74 to 51,760 over the test period. While doors were opened and closed within short periods of time much more frequently, longer door-open times contributed more to the total amount of time that the doors were open. This shows that normal use of the doors where they are open for short periods of time did not have a large impact on the overall performance of the doors. All of the occupancies had doors that were left open for longer than one day with the exception 
of the apartment/condo buildings, which may be a result of the emphasis for overnight security in these buildings.

Table 4. Summary statistics comparing working and non-working hours for the 52 door sample.

\begin{tabular}{rcc|cc} 
& \multicolumn{2}{c|}{$\mathbf{0 8 0 0}$ to 1700 } & \multicolumn{2}{c}{$\mathbf{1 7 0 1}$ to 0759 } \\
Type of building & Mean & St. dev. & Mean & St. dev. \\
\hline Rest home & 0.95 & 0.05 & 0.95 & 0.05 \\
Hotel/backpackers & 0.88 & 0.17 & 0.91 & 0.15 \\
Apartment/condo & 0.86 & 0.30 & 0.86 & 0.30 \\
Boarding house/dorm & 0.85 & 0.32 & 0.85 & 0.32 \\
\hline Total & 0.89 & 0.20 & 0.90 & 0.19
\end{tabular}

Table 5. Summary statistics comparing weekend and weekday probabilities that doors were closed for the 52 door sample.

\begin{tabular}{rcc|cc} 
& \multicolumn{2}{c|}{ Weekend } & \multicolumn{2}{c}{ Weekday } \\
Type of building & Mean & St. dev. & Mean & St. dev. \\
\hline Rest home & 0.95 & 0.06 & 0.95 & 0.05 \\
Hotel/backpackers & 0.89 & 0.16 & 0.90 & 0.16 \\
Apartment/condo & 0.86 & 0.30 & 0.86 & 0.30 \\
Boarding house/dorm & 0.85 & 0.33 & 0.85 & 0.32 \\
\hline Total & 0.89 & 0.19 & 0.90 & 0.19
\end{tabular}

The influence of a form of the "Hawthorne Effect" cannot be ruled out on the results. The Hawthorne Effect describes the potential for human behaviour to be influenced by the fact that a certain aspect is given attention, first attributed after 1920s studies on worker productivity under varying lighting conditions conducted in the Western Electric Hawthorne Plant located in Illinois [18]. In this case, the building owners or managers had to be notified that the door position logging devices were being placed in their buildings. This could have influenced their behaviour in different ways: they may have been made more aware of the need to keep fire doors closed by the fact that the study was being conducted and thus adjusted their behaviour based on this change in knowledge, the presence of the devices may have been a reminder to the building occupants to close the door if they happened to observe a device when passing through a door, or they may have wanted to demonstrate that their building was meeting fire safety objectives by adjusting their behaviour and keeping the doors closed.

This effect could also be present for "snap-shot" inspection type data collection if any of the building occupants received information that an inspection was taking place prior to the inspection. A way to avoid this issue for future data collection would be to embed the devices in fire doors so they are not visible when they are installed and monitor the position over the lifetime of the doors. It is unknown if there would be any legal implications of tracking door position without notifying the building personnel. It might have to be written into the building regulations or Compliance Schedule requirements to be successfully implemented. 


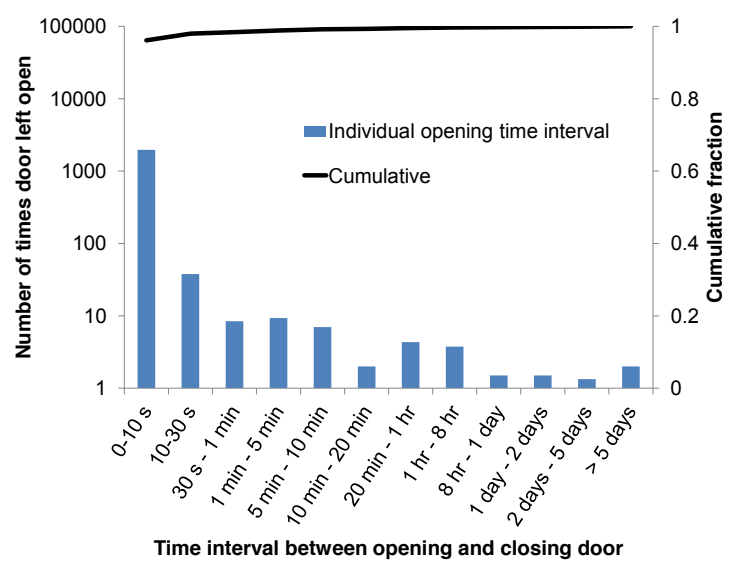

(a) Rest home

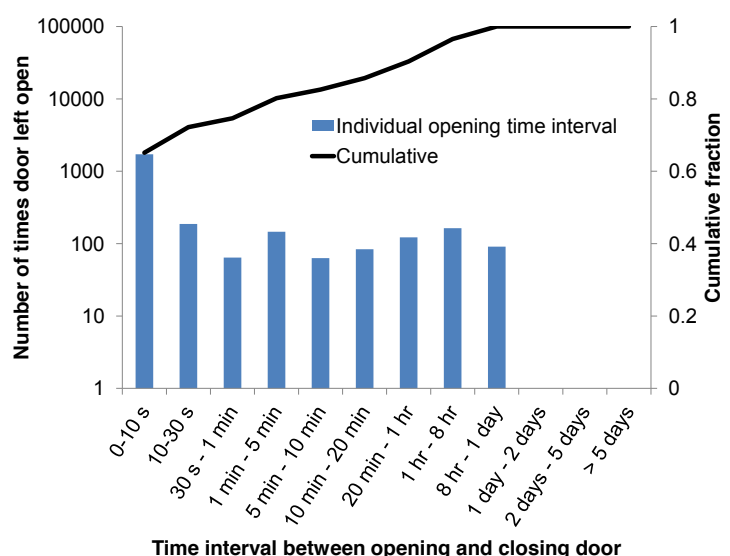

(c) Apartment/condo

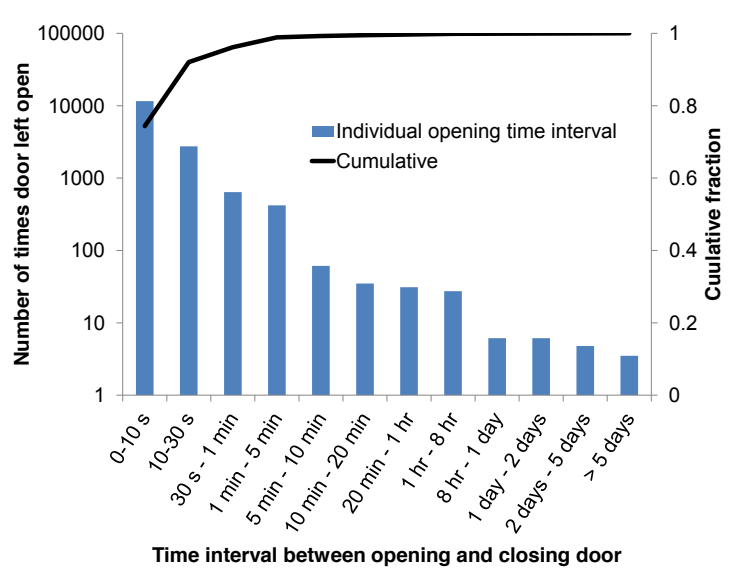

(b) Hotel/backpackers

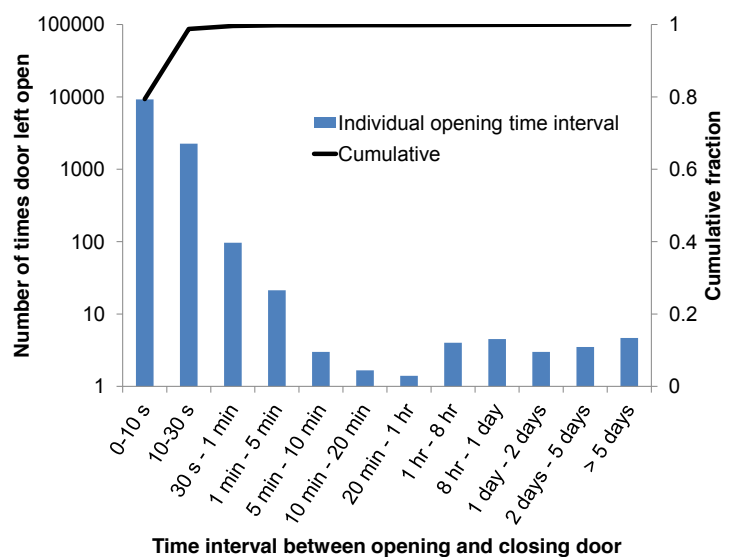

(d) Boarding house/dorm

Fig. 6. The mean number of times that doors were opened by open/close time interval.

\section{CONCLUSIONS}

A new method of collecting data on likelihood of doors being open has been developed which leverages inexpensive modern microcontroller and sensor technology. Long-term door reliability data for 52 fire or smoke doors with self-closers in four types of buildings including rest homes, hotels/backpackers, apartments/condos, and boarding houses/dorms. Door reliability is found to be skewed, with the majority of doors closed most of the time and a few doors open for long periods of time. The average door reliability is found to be higher than observed in a 1970 UK study.

Rest home doors are found to be closed most often followed sequentially by hotel/backpackers, apartment/condo, and boarding house/dorm doors. Other than for hotel/backpacker building types, there is negligible difference between working hours and non-working hours and between weekends and weekdays.

It is not possible to determine if the building occupants' behaviour was influenced by the study itself. Future data collection would have to be undertaken without the knowledge of the building occupants to eliminate this source of uncertainty in the validity of the data. Future work could include extending the number of doors being assessed and the duration of the data recording. It would also be interesting to examine whether doors are used to connect to staircases or link corridors as the fire risk would appear to be much higher if the doors connected to staircases are open. 


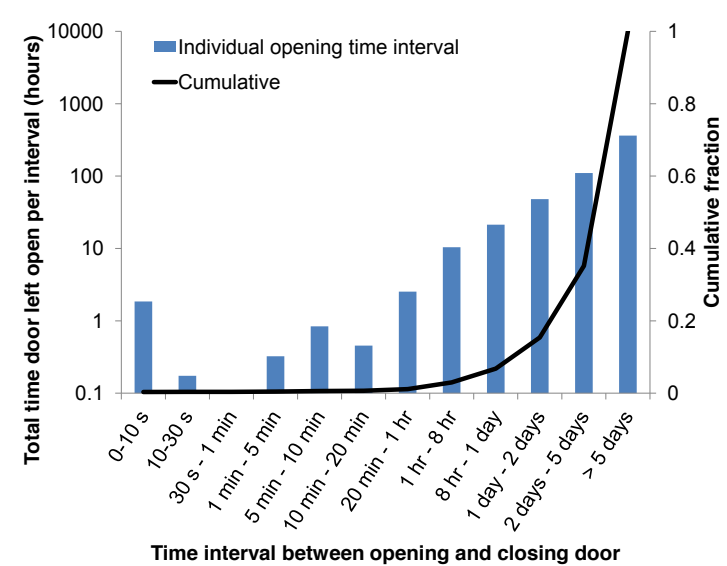

(a) Rest home

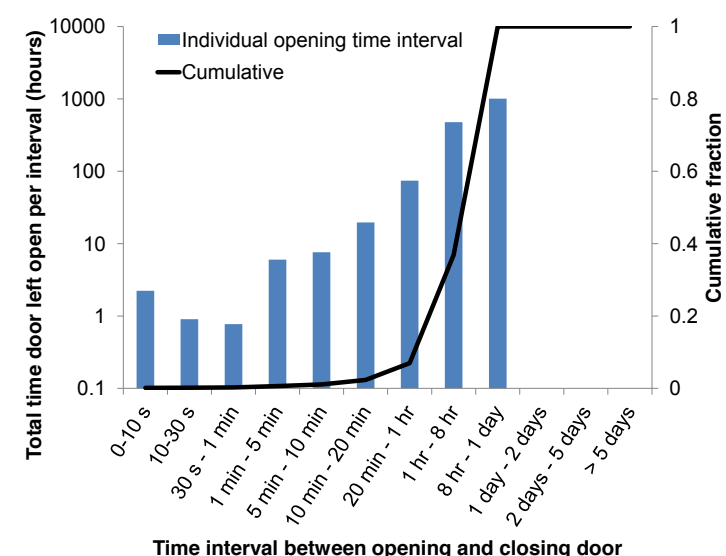

(c) Apartment/condo

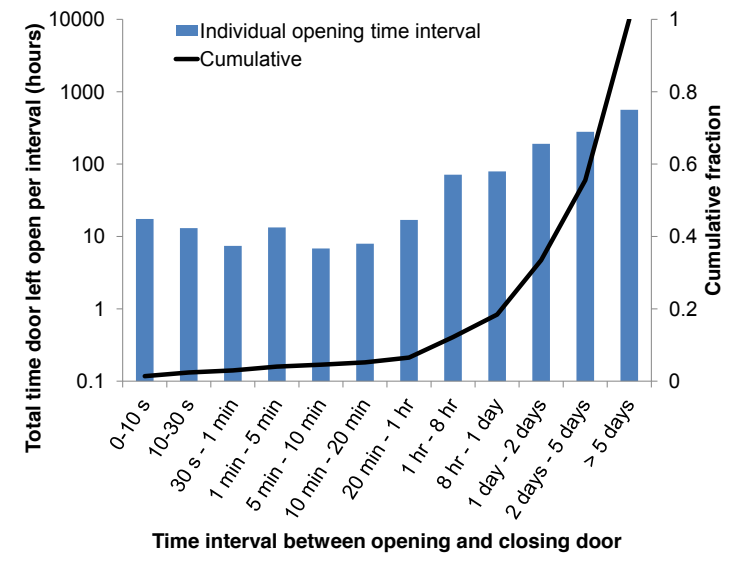

(b) Hotel/backpackers

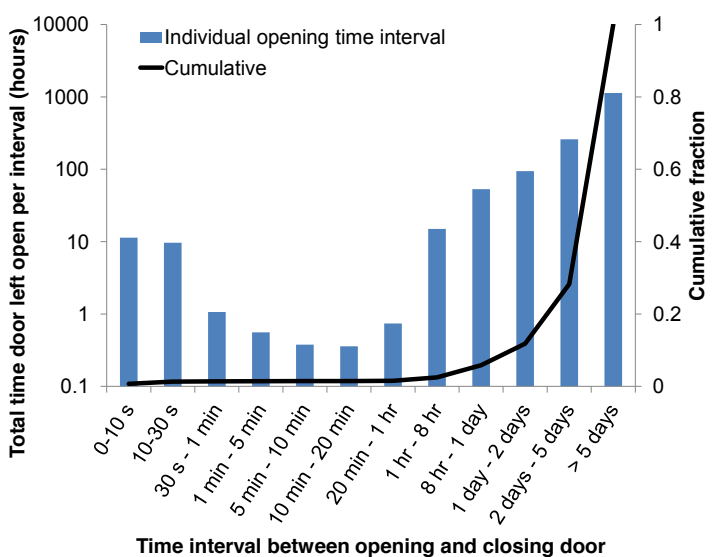

(d) Boarding house/dorm

Fig. 7. The mean cumulative time that doors were left open when cycled from open to closed for the specified intervals of time.

\section{ACKNOWLEDGEMENTS}

The authors would like to thank Tim Crow and Forrest McKerchar for their assistance in the developing the door position data logger prototype, designing the PCB, assembling the devices and writing the basic embedded software. The authors would also like to thank Roy Dobson and Charlie Loughnan from Fire Fighting Pacific for their help in identifying the buildings that were used for the field measurements. The research was supported by the Building Research Levy and the previously existing Foundation for Research, Science and Technology (FRST).

\section{REFERENCES}

[1] Heselden, A. J. M., and Baldwin, R., (1978) The Movement and Control of Smoke on Escape Routes in Buildings. Fire Technology 14(3): 206-222, http://dx.doi.org/10.1007/BF01983055

[2] Palmer, D.L., “Should Bedroom Doors be Open or Closed While People are Sleeping?," Master's project report, University of Canterbury, Christchurch, New Zealand, 1999, 107 p. 
[3] Lustig, R. E., (1958) "Importance of Doors and Windows in Fires in Domestic Dwellings," Fire Research Note No. 383, Fire Research Station, Borehamwood, UK, 1958, 5 p.

[4] Department of Building and Housing, C/VM2 Verification Method: Framework for Fire Safety Design For New Zealand Building Code Clauses C1-C6 Protection from Fire, Department of Building and Housing, Wellington, New Zealand, 2012.

[5] Yung, D., Hadjisophocleous, G. V., and Proulx, G., (1999) A Description of the Probabilistic and Deterministic Modelling Used in FiRECAM, International Journal on Engineering PerformanceBased Fire Codes 1(1): 18-26.

[6] Wade C., Baker G., Frank K., Robbins A., Harrison R., Spearpoint M., and Fleischmann, C., "BRISK User Guide and Technical Manual,” BRANZ Study Report SR 282, BRANZ Ltd, Judgeford, Porirua City, New Zealand, 2013, 130 p.

[7] Bukowski, R.W., Budnick, E.K. and Schemel, C.F., "Estimates of the Operational Reliability of Fire Protection Systems," Proceedings of the Third International Conference on Fire Research and Engineering (ICFRE3), Society of Fire Protection Engineers, Boston, MA, 1999, pp. 87-98.

[8] PD 7974-7:2003 - The Application of Fire Safety Engineering Principles to Fire Safety Design of Buildings, Probabilistic Risk Assessment, British Standards Institution, London, UK, 2003, 80 p.

[9] Yoshiro Y., Ebihara, M., and Notake H., (2000) "Fire Safety Design and Fire Risk Analysis Incorporating Staff Response in Consideration of Fire Progress Stage,” NISTIR 6588, National Institute of Standards and Technology, Gaithersburg, MD, USA, 11 p.

[10] Fernandez, P., (1996) Probabilistic Fire Analysis Capabilities, Applications, and Weak Points, Nuclear Engineering and Design 167(1): 77-83, http://dx.doi.org/10.1016/S0029-5493(96)01243-5

[11] Viera, D.L., (1992) Fire Doors: A Potential Weak Link in the Protection Chain, Fire Technology 28(2): 177-180, http://dx.doi.org/10.1007/BF01857945

[12] Ramachandran, G., "Fire Doors and Losses in Large Fires," Fire Research Note No. 690, Fire Research Station, Borehamwood, UK, 1968, 2 p.

[13] Langdon Thomas, G. J. and Ramachandran, G., (1970) Improving the Effectiveness of the Firecheck Door, Fire International 3(27): 73-80.

[14] Konvalin, C., Compensating for Tilt, Hard-Iron, and Soft-Iron Effects, Sensors Magazine, 2009, $9 \mathrm{p}$.

[15] Bullock, R., "Least-Squares Circle Fit," Developmental Testbed Center, Boulder, CO, USA, 2006, 3 p.

[16] Ministry of Business, Innovation and Employment, The Building Act, Wellington, New Zealand, 2004.

[17] Department of Building and Housing, Compliance Schedule Handbook, Wellington, New Zealand, 2007, $56 \mathrm{p}$

[18] Levitt, S. D. and List, J. A., (2011) Was there Really a Hawthorne Effect at the Hawthorne Plant? An Analysis of the Original Illumination Experiments, American Economic Journal: Applied Economics 3(1): 224-238, http://dx.doi.org/10.1257/app.3.1.224 